\title{
Kinetic modeling of the multistep hydrolysis-dehydration of cellulose to platform molecules over a solid carbon acid catalyst in pure water
}

\author{
Nikolay Gromov, ${ }^{1,2^{*}}$ Oxana Taran, ${ }^{1,3}$ Cyril Aymonier, ${ }^{4}$ Valentin Parmon ${ }^{1}$ \\ ${ }^{1}$ Boreskov Institute of Catalysis SB RAS, 5, av. Lavrentiev, 630090, Novosibirsk, Russia. \\ ${ }^{2}$ Novosibirsk State Technical University, 630092, Karl Marx av., 20, Novosibirsk, Russia \\ ${ }^{3}$ Institute of Chemistry and Chemical Technology SB RAS, FRC Krasnoyarsk Science Center SB \\ RAS, 660036, Akademgorodok 50/24, Krasnoyarsk, Russia. \\ ${ }^{4}$ CNRS, Univ. Bordeaux, Bordeaux INP, ICMCB, UMR5026, 33600 Pessac, France. \\ *corresponding author: gromov@catalysis.ru
}

\begin{abstract}
The present study was devoted to a kinetic modeling of cellulose hydrolysis-dehydration into platform molecules (glucose and 5-hydroxymethylfurfural) over a carbon solid acid catalyst. Cellulose depolymerization and transformations of the main process intermediates were experimentally studied under hydrothermal conditions in pure water over a catalyst based on sulfonated Sibunit material at $180{ }^{\circ} \mathrm{C}$ in a batch reactor. Based on the data obtained, the 18-step kinetic scheme of the process which included the main reaction pathways was proposed as well as the reaction constants were determined. Kinetic parameters showed that solid acid carbon catalysts seems to be more suitable than soluble ones for the production of 5-HMF from sugars. Proposed software modeling of cellulose hydrolysis-dehydration described the experimental results obtained with a sufficient accuracy.
\end{abstract}

\section{Keywords}

Cellulose, hydrolysis-dehydration, kinetics, modeling, Sibunit, carbon catalyst 


\section{Article Highlights}

- Hydrolysis-dehydration of cellulose and process intermediates into glucose and 5-HMF platform molecules was studied

- Reactions were carried out over Sibunit carbon catalyst at $180{ }^{\circ} \mathrm{C} .18$-step kinetic model of the process was proposed

- Software modeling described the cellulose hydrolysis-dehydration with a sufficient accuracy

\section{Acknowledgments}

This work was supported by the Russian Foundation for Basic Research (Project 17-5316027) and Russian-French GDRI “Biomass”. 


\section{Declarations}

\section{Funding}

This work was supported by the Russian Foundation for Basic Research (Project 17-5316027) and Russian-French GDRI "Biomass".

\section{Conflict of interest}

The authors declare that they have no conflict of interest.

\section{Availability of data and material (data transparency)}

Not applicable

\section{Code availability}

Not applicable 


\section{Introduction}

In the recent years research efforts have been focused on cellulose as a promising alternative raw material for chemical and fuel industries. Unlike oil, gas and coal traditional recourses, cellulose has a lot of advantages which are renewability, availability, comparatively low cost, as well as an absence of competition with the food industry for land and other resources [1-5]. The cellulose resources may be agricultural and wood processing wastes. Hydrolytic cellulose processing is one of the most actual fields of fine chemistry. This method of cellulose transformation, itself or combined with other processes, for example oxidation [6-8] or reduction [8-11], is suitable for the synthesis of valuable chemicals and non-petroleum fuels $[2,12,13]$. Cellulose hydrolysis-dehydration can be applied in the production of platform compounds: glucose, 5-hydroxymethylfurfural (5-HMF) and levulinic acid $[2,5,8,12,14]$. The process proceeds efficiently in the presence of solid acid catalysts such as metal oxides [15], nanodisperse metals [16], resins [15], and modified carbon materials [17]. Recently we reported solid acid catalysts based on Sibunit carbon material which demonstrated high activity in hydrolysis-dehydration of cellulose to glucose and 5-HMF [18].

Research facilities in the field of cellulose hydrolysis-dehydration are not only aimed at the search for promising catalysts, process conditions and significant yields of the target products, but also search process mechanisms and kinetic parameters [1]. The kinetic studies and modeling of cellulose depolymerization into various chemicals are not trivial task. Cellulose hydrolysisdehydration is a complex multistep process. It proceeds through a lot of pathways and a large number of intermediates can be formed [19]. Nevertheless, the simplest two-stage model of cellulose depolymerization was suggested in 1945 [20]. It included the cellulose conversion to the target products at the first stage and the decomposition of the target product at the second stage [2129]:

Polysaccharide $\stackrel{\mathrm{k}_{1}}{\longrightarrow}$ Hydrolysis products $\stackrel{\mathrm{k}_{2}}{\longrightarrow}$ Decomposition products 
Abatzoglou and co-authors reported a more complex kinetic model which involved separate stages of polysaccharide transformation into water-soluble oligosaccharides, their hydrolysis and the decomposition of the target products [30-32]:

Polysaccharide $\stackrel{\mathrm{k}_{1}}{\longrightarrow}$ Oligosaccharides $\stackrel{\mathrm{k}_{2}}{\longrightarrow}$ Hydrolysis products $\stackrel{\mathrm{k}_{3}}{\longrightarrow}$ Decomposition products

Some other models reported previously took into account amorphous and crystalline domains in cellulose structure which were respectively easy and hard to hydrolyze $[1,24,33,34]$ :
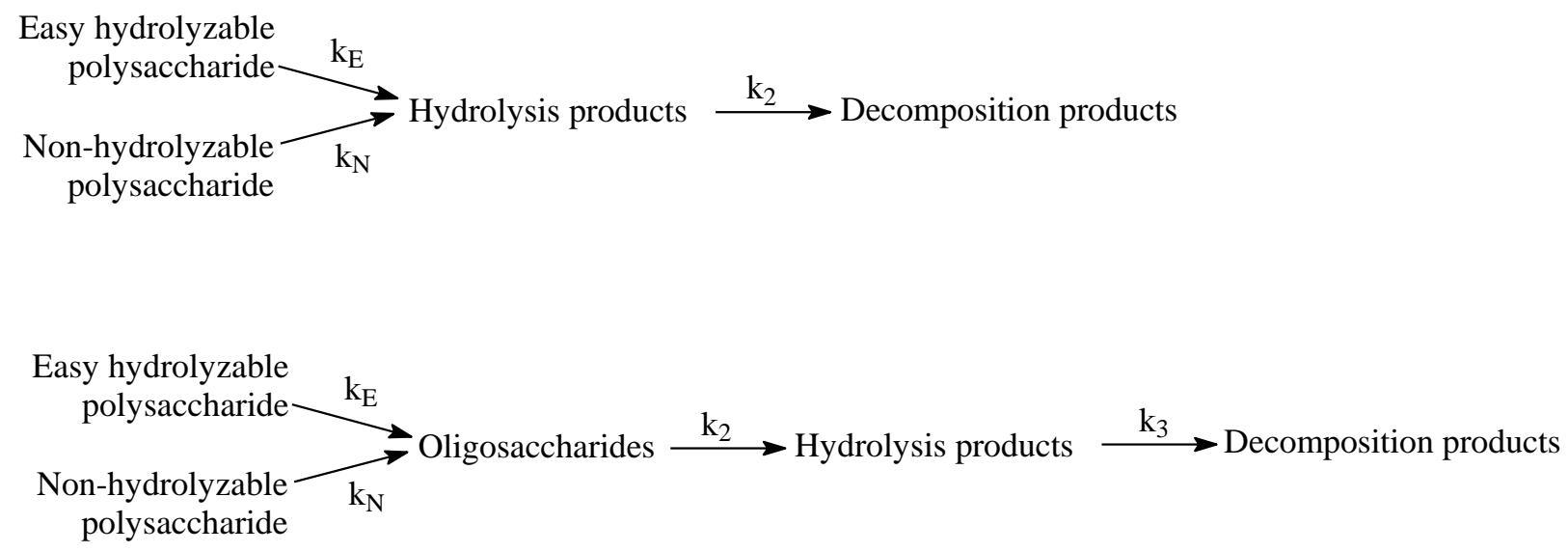

Kinetic equations of these models are used for calculating reaction constants, activations energies of stages and pre-exponential factors of kinetic constants. When modeling kinetics, all reactions involved are usually considered as irreversible and first order [20,33]. However, each kinetic model can be additionally modified for the observed experimental kinetic curves to be described more accurate. In particular, some stages can be regarded as reversible [30,35], as well as side reactions of cellulose hydrolysis-dehydration can be included [14]. Conner and co-authors suggested a model of cellulose hydrolysis-dehydration which involved two reversible transformations of glucose into disaccharides and anhydrosugars [36]. Bahari et al. found kinetic parameters of $\beta$-glucosane and mannoprotein conversions to 5-HMF [37]. Polysaccharide transformation scheme included five first-order stages [37]. Cantero et al. studied the fast cellulose hydrolysis-dehydration in supercritical water to determine kinetic parameters and activation energies. The kinetic scheme was rather complex but they did not report the kinetic modeling of the process [38]. Murzin and coauthors studied transformations of arabinogalactan polysaccharide using a scheme consisted of complex zero-order interconversions of the process intermediates. The kinetic scheme described the 
formation of furfural and 5-HMF as the major products via the formation of soluble oligosaccharides followed by their hydrolysis-dehydration. Several other routes of intermediate and target product transformations were also taken into consideration. The scheme was treated using a special software.

The knowledge on the mechanism and kinetic regularities are certainly helpful for better understanding of the cellulose hydrolysis-dehydration and for predicting the optimal process conditions. Kinetic investigations are useful for scaling-up the laboratory process to industry. The kinetic schemes of the production of glucose and/or 5-HMF from cellulose reported elsewhere are usually based on simple kinetic models and involve only the main products and several process stages [21-23,31,39]. More complex kinetic schemes are rarely used because of the necessity of special software applications. The present study was focused on software modeling of the kinetics involving 18 stages of the cellulose hydrolysis-dehydration carried out over a solid acid catalyst based on sulfonated carbon material Sibunit.

\section{Experimental}

\subsection{Chemicals}

5-HMF (Sigma-Aldrich), D-fructose (Sigma-Aldrich), D-mannose (Sigma-Aldrich), Dglucose (Reahim, Moscow, Russia), D-cellobiose (Alfa Aesar), levulinic acid (Acros Organics) were purchased and used as HPLC standards. Milli-Q water (Millipore, France) was used for all experiments. Microcrystalline pure cellulose (Vekton, Saint-Petersburg, Russia) was mechanically activated before all the experiments. The polysaccharide was milled in a discrete action planetary mill Pulverizette 5 (Fristch, Germany) as we described previously [18]. The crystallinity of the activated sample revealed by XRD (BrukerD8 Advabced, Germany) was 37\%. The measurements of crystallinity are described in detail in the Supporting Information (SI) and our previous work [40]. The particle size measured by optical microscopy (Zeiss - Axiostar plus microscope equipped 
with a photocamera, Germany) was equal to $13 \pm 6 \mu \mathrm{m}$. The average diameter of cellulose particles was calculated as the mean diameters of 100 particles.

\subsection{Preparation of Sibunit carbon acid catalyst}

The catalyst was prepared from mesoporous graphite-like carbon material (commercial name Sibunit, Omsk, Russia) via sulfonation in fuming $\mathrm{H}_{2} \mathrm{SO}_{4}$ as we reported previously [18]. Before preparing the catalyst, the carbon material was washed several times with boiling Milli-Q water. Then Sibunit was grinded and sifted through several sieves. The fraction of 560-940 $\mu \mathrm{m}$ was collected and washed again several times with boiling Milli-Q water. The typical procedure for preparing catalyst was the following. $1 \mathrm{~g}$. of the grinded carbon was placed into a glass vessel. 15 $\mathrm{mL}$ of fuming $\mathrm{H}_{2} \mathrm{SO}_{4}$ was added. The vessel was heated upto $200{ }^{\circ} \mathrm{C}$. The sulfonation time was 10 h. When the treatment was finished, the flask was cooled down. The catalysts was separated from the sulfuric acid, washed with boiling Milli-Q water and air-dried [18]. The catalyst was characterized by TEM, XRF, $\mathrm{N}_{2}$ adsorption and acid-base titration with $\mathrm{NaOH}$ [18]. From TEM and low-temperature $\mathrm{N}_{2}$ adsorption data, the carbon catalyst consisted of spherical carbon globules with the specific surface area of $400 \mathrm{~m}^{2} \cdot \mathrm{g}^{-1}$. The catalyst surface acidity equal to $0.40 \mathrm{mmol} \cdot \mathrm{g}^{-1}$ was determined by acid-base titration. Before any catalytic experiment the catalyst was treated under hydrothermal conditions to remove weakly fixed acidic groups. Analysis of the treated catalyst by XRF revealed high stability of the sulfur content in the catalyst at the temperature up to $200{ }^{\circ} \mathrm{C}$ [18].

\subsection{Catalytic tests}

Hydrolysis-dehydration of cellulose over the Sibunit carbon catalyst was studied in a batch hastelloy autoclave (Autoclave Engineers, USA) at $180{ }^{\circ} \mathrm{C}, 1 \mathrm{MPa}$ of $\mathrm{Ar}$, under $1500 \mathrm{rpm}$ stirring. The scheme of the experimental setup is shown in Fig. 1. Cellulose, catalyst and deionized Milli-Q water were placed into the reactor. Both the catalyst and cellulose concentrations were $10 \mathrm{~g} \cdot \mathrm{L}^{-1}$. The volume of the reaction mixture was $45 \mathrm{~mL}$. The autoclave was closed, the air was replaced with 
argon. The reactor was heated to $180^{\circ} \mathrm{C}$, whereupon the reaction was started. Aliquots $(\sim 1 \mathrm{~mL})$ of the reaction mixture were drawn from the reactor in $0,1,2,3,5$ and 7 hours for HPLC analysis [18].

The transformations of cellulose hydrolysis-dehydration intermediates (cellobiose, glucose, fructose, 5-HMF, etc.) were also studied. Experiments in the batch reactor were carried out in the same way as cellulose transformation.

Aliquots of the reaction mixtures were analyzed by HPLC Shimadzu Prominence LC-20 (Japan) setup equipped with Rezex ROA-Organic Acids (Phenomenex, $300 \mathrm{~mm} \cdot 5.0 \mathrm{~mm}$ ) column thermostated at $40{ }^{\circ} \mathrm{C}$ and refractive index and diode array detectors. The eluent was $1.25 \mathrm{mM}$ $\mathrm{H}_{2} \mathrm{SO}_{4}$, the flow rate was $0.6 \mathrm{~mL} \mathrm{~min}^{-1}$.

Product yields (Y) were calculated according to the formula (1):

$$
Y=\frac{C_{\text {Product }} \cdot V}{N \times\left(m_{\text {cellucose }} / M_{\text {glucan }}\right)} \times 100
$$

where $Y$ was a yield $(\%), C_{\text {Product }}\left(\mathrm{mol} \mathrm{L}^{-1}\right)$ was the concentration of a product, $V$ was the solution volume (L), $N$ was a stoichiometric coefficient between a glucan unit and a product (1 for glucose

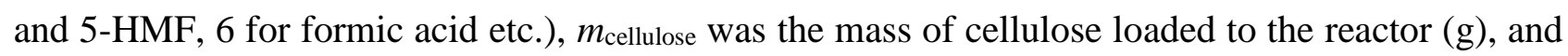
$M_{\text {glucan }}$ was the molar mass of a glucan unit in cellulose $\left(162 \mathrm{~g} \cdot \mathrm{mol}^{-1}\right)$.

To evaluate cellulose consumption, the reaction was carried out without drawing down any aliquots during 1, 2, etc. hours. The solids were separated from the reaction mixture by centrifugation, dried and weighted.

Cellulose consumption was calculated as following (2):

$$
X=\frac{m_{0}-m}{m_{0}}
$$

where $X$ was cellulose consumption (\%), $m$ and $m_{0}$ were masses of cellulose $(\mathrm{g})$ after and before the reaction, respectively. 


\section{Results and Discussion}

\subsection{Hydrolysis-dehydration of cellulose and main process intermediates}

Cellulose hydrolysis-dehydration was experimentally studied using a batch reactor at $180{ }^{\circ} \mathrm{C}$ under inert atmosphere (argon pressure was $1 \mathrm{MPa}$ ) in the presence of a solid acid carbon catalyst. HPLC was used for analysis of the reaction mixture (Fig. 2 a). The maximal yield of glucose (45.9 $\%$ ) was achieved in $2 \mathrm{~h}$ of the reaction. The maximal yield of 5-HMF was $18 \%$ (5 h reaction time). It is mentioned above that cellulose transformation is a complex multistep process involving a large number of stages and intermediates [41]. In studying the complex chemical system, it is important to determine the basic process mechanism and all the reaction pathways, to identify intermediates and rate-determining stages. To model the cellulose hydrolysis-dehydration process, we proposed the kinetic scheme that took into account all the intermediates detected as well as the reactions between them (Scheme 1).

Main stages of the cellulose hydrolysis-dehydration process were separately studied. Experiments where intermediates were substrates were carried out over the carbon catalyst in the batch autoclave. The process conditions were the same as ones for cellulose transformation $\left(180{ }^{\circ} \mathrm{C}\right.$, $1 \mathrm{MPa}$ of Ar). Hydrolysis-dehydration of cellobiose, isomerization-dehydration of glucose, fructose and mannose, degradation of furfural and 5-HMF were separately investigated. The experimental data obtained are presented in Fig. 2 and Fig. S1. Hydrolysis-dehydration of cellobiose disaccharide made possible to determine the initial rate of hydrolysis of the $\beta$-(1-4)-glycosidic bond. Quick consumption of cellobiose was established (Fig. S1 a). The conversion of the disaccharide achieved $55 \%$ at the beginning of the reaction. Cellobiose was spent completely in $0.5 \mathrm{~h}$. This confirmed that the hydrolysis was a very fast reaction, and the overall kinetics of the cellulose hydrolysis-dehydration was limited by the cellulose depolymerization and formation of watersoluble oligosaccharides. Cellobiose hydrolysis was revealed to be an irreversible process. The kinetic model fitted the experimental data when repolymerization constant was close to zero. The first order of the $\beta$-(1-4)-glycosidic bond hydrolysis used for calculations in our study agreed with 
the investigations reported previously. Thus, Saeman showed that the reaction order of hydrolytic cellulose transformations was in the range of 0.7-1.3 [20]. Bobleter and Bonn reported the first order of the cellobiose hydrolysis to glucose [42]. Experimental data demonstrated that glucose consumption was much slower than fructose one. In case of glucose hydrolysis, fructose was practically not accumulated and converted rapidly to 5-HMF. The yield of 5-HMF achieved $33 \%$ in the experiment where fructose was spent. This value was higher than the 5-HMF yield reached from glucose (16\%) (Fig. $2 \mathrm{c}$ and d). The high yields of 5-HMF derived from fructose were reported previously $[41,43]$. In the experiment with fructose, 5-HMF accumulation stopped as soon as fructose was fully converted. Glucose transformation proceeded slower compared with fructose consumption and resulted in lower 5-HMF yield. This was the evidence that glucose isomerization to fructose was the limiting stage of the process while fructose dehydration to 5-HMF was a fast reaction (Scheme 1). The consumptions of glucose and fructose plotted in logarithmic coordinates had linear dependences on the process time (Fig. S2). The first reaction order of sugar conversions was reported elsewhere [20,44-46]. According to the experimental data, mannose was formed from both glucose and fructose. The experiment with 5-HMF as a substrate revealed low stability of the compound. The conversion of 5-HMF reached $70 \%$ in 7 h (Fig. 2 e). The formation of sugars was not observed what confirmed that dehydration of fructose to 5-HMF was an irreversible reaction. On the other hand, levulinic and formic acids were not accumulated from 5-HMF in significant yields. These data confirmed the transformation of 5-HMF via alternative pathway of hightemperature polycondensation to give side products [47-49]. When fructose and 5-HMF were used as substrates (Fig. 2 c and e), furfural was demonstrated only to form from fructose but not from 5HMF. Minor yields of furfural equal to 1-2 \% were observed. The kinetics of furfural transformation was also investigated (Fig. S1 b). Compared to 5-HMF, furfural demonstrated better stability under reaction conditions. Negligible yield of formic acid from furfural was detected, accumulation of sugars was not observed. 


\subsection{Kinetic modeling of the cellulose hydrolysis-dehydration}

All the identified intermediates and products were added to the scheme of the reaction (Scheme 1). The constants of the reactions and chemical interactions were revealed from the experimental kinetic curves (Table 1). The kinetic modeling was based on the following assumptions. The first orders of all the stages were assumed as consumptions of all the intermediates had a linear dependence in $\ln \left(\mathrm{C} / \mathrm{C}_{0}\right)$ vs time coordinates (Fig. S2). The rates of proton adsorption/desorption during cellulose dissolution in water and the diffusion rates to the surface of the Sibunit solid catalyst were high enough and the reaction constants revealed were of chemical interactions but not of diffusion.

Based on the experimental data (Scheme 1), a following system of differential equations was proposed for modeling the kinetic curves.

$$
\begin{aligned}
& \text { (I) } \frac{\mathrm{d}}{\mathrm{dt}} \mathrm{X}(\mathrm{t})=-\mathrm{k}_{0} \cdot(1-\mathrm{X}(\mathrm{t})), \\
& \text { (II) } \frac{\mathrm{d}}{\mathrm{dt}} \operatorname{Olig}(\mathrm{t})=\mathrm{k}_{0} \cdot(1-\mathrm{X})(\mathrm{t})-\mathrm{k}_{1} \cdot \operatorname{Olig}(\mathrm{t}), \\
& \text { (III) } \frac{\mathrm{d}}{\mathrm{dt}} \operatorname{Cellb}(\mathrm{t})=\mathrm{k}_{1} \cdot \operatorname{Olig}(\mathrm{t})-\mathrm{k}_{2} \cdot \operatorname{Cellb}(\mathrm{t}), \\
& \text { (IV) } \frac{\mathrm{d}}{\mathrm{dt}} \operatorname{Glu}(\mathrm{t})=\mathrm{k}_{2} \cdot \operatorname{Celb}(\mathrm{t})+\mathrm{k}_{31} \cdot \operatorname{Fru}(\mathrm{t})+\mathrm{k}_{43} \cdot \operatorname{Mann}(\mathrm{t})-\left(\mathrm{k}_{3}+\mathrm{k}_{34}+\mathrm{k}_{30}\right) \cdot \mathrm{Glu}(\mathrm{t}), \\
& \text { (V) } \frac{\mathrm{d}}{\mathrm{dt}} \operatorname{Fru}(\mathrm{t})=\mathrm{k}_{3} \cdot \operatorname{Glu}(\mathrm{t})+\mathrm{k}_{41} \cdot \operatorname{Man}(\mathrm{t})-\left(\mathrm{k}_{31}+\mathrm{k}_{4}+\mathrm{k}_{5}+\mathrm{k}_{6}+\mathrm{k}_{50}\right) \cdot \operatorname{Fru}(\mathrm{t}), \\
& \text { (VI) } \frac{\mathrm{d}}{\mathrm{dt}} \operatorname{Man}(\mathrm{t})=\mathrm{k}_{4} \cdot \operatorname{Fru}(\mathrm{t})+\mathrm{k}_{34} \cdot \operatorname{Glu}(\mathrm{t})-\left(\mathrm{k}_{41}+\mathrm{k}_{43}+\mathrm{k}_{40}\right) \cdot \mathrm{Man}_{(\mathrm{t})}, \\
& \text { (VII) } \frac{\mathrm{d}}{\mathrm{dt}} 5-\mathrm{HMF}(\mathrm{t})=\mathrm{k}_{5} \cdot \operatorname{Fru}(\mathrm{t})-\left(\mathrm{k}_{7}+\mathrm{k}_{8}\right) \cdot 5-\mathrm{HMF}(\mathrm{t}), \\
& \text { (VIII) } \frac{\mathrm{d}}{\mathrm{dt}} \operatorname{Furf}(\mathrm{t})=\mathrm{k}_{6} \cdot \operatorname{Fru}(\mathrm{t})-\left(\mathrm{k}_{9}+\mathrm{k}_{11}\right) \cdot \operatorname{Furf}(\mathrm{t}) \\
& \text { (IX) } \frac{\mathrm{d}}{\mathrm{dt}} \mathrm{LA}(\mathrm{t})=\mathrm{k}_{7} \cdot 5-\mathrm{HMF}(\mathrm{t})-\mathrm{k}_{12} \cdot \operatorname{LA}(\mathrm{t}), \\
& \text { (X) } \frac{\mathrm{d}}{\mathrm{dt}} \operatorname{FA}(\mathrm{t})=\mathrm{k}_{7} \cdot 5-\mathrm{HMF}(\mathrm{t})+\mathrm{k}_{9} \cdot \operatorname{Furf}(\mathrm{t})-\mathrm{k}_{10} \cdot \operatorname{FA}(\mathrm{t}),
\end{aligned}
$$

where Cellb was Cellobiose, Glu was Glucose, Fru was Fructose, Man was Mannose, Furf Furfural, LA was Levulinic acid, FA was Formic acid. X was a cellulose conversion applied instead of cellulose concentration. $X$ value was used as cellulose was a insoluble compound $[20,50]$. 
The constant $\mathrm{k}_{0}$ of cellulose dissolution determined from the cellulose consumption measured according to the formula (2) was equal to $16 \cdot 10^{-3} \mathrm{~min}^{-1}$. The constant meaning was low enough compared to $\mathrm{k}_{2}$ determined experimentally from cellobiose transformations $\left(0.11 \mathrm{~min}^{-1}\right)$. This indicated that cellulose transformation to water soluble oligosaccharides but not hydrolysis itself was a limiting stage of cellulose processing. When modeling cellulose hydrolysis-dehydration the value of $\mathrm{k}_{1}$ of water-soluble oligomer hydrolysis was assumed to be equal to $\mathrm{k}_{2}$ as both constants described the cleavage of the $\beta$-(1-4)-glycosidic bond (Scheme 1). Hydrolysis constant was more than other constants by an order of magnitude. Hence, hydrolysis proceeded at a very high rate. The revealed constant $\mathrm{k}_{3}$ of isomerization of glucose to fructose was lower than the observed constant $\mathrm{k}_{5}$ of fructose dehydration to 5-HMF by a factor of 2.4. That demonstrated glucose consumption to fructose was limited by isomerization to result in a decrease in the yield of 5-HMF. Constants $\mathrm{k}_{3}$ determined from kinetic experiments with glucose as a substrate was $8.0 \cdot 10^{-3}$. The value of $\mathrm{k}_{31}$ was evaluated from thermodynamic data. According to Tewari and Goldberg, equilibrium constant for glucose-fructose isomerization at $180{ }^{\circ} \mathrm{C}$ is 2.6 [51]. This came to $\mathrm{k}_{31}=\mathrm{k}_{3} / \mathrm{K}=8.0 \cdot 10^{-3} / 2.6=3.07 \cdot 10^{-3} \mathrm{~min}^{-1}$. Delidovich and co-authors reported that a certain combination of the equilibrium constants for the interconversions of monosaccharides was equal to 1 [52]. Thus, $\frac{\mathrm{k}_{3} \cdot \mathrm{k}_{4} \cdot \mathrm{k}_{43}}{\mathrm{k}_{31} \cdot \mathrm{k}_{34} \cdot \mathrm{k}_{41}}=1$ equation gave $\mathrm{k}_{4}$ value of $7.4 \cdot 10^{-3} \mathrm{~min}^{-1}$.

When modeling the cellulose hydrolysis-dehydration additional degradation of glucose, fructose and mannose monosaccharides was presumed via pathways with rate constants $\mathrm{k}_{30}, \mathrm{k}_{50}$ and $\mathrm{k}_{40}$, respectively. Contradictory data on an existence of these side transformations were shown previously. Thus, fructose transformation to glyceraldehydes and then to pyruvaldehyde and lactic acid was revealed by some researchers $[38,45,48,53,54]$. On the other hand, some doubt of the occurrence of these routes in the presence of an acid catalyst at temperatures below $270{ }^{\circ} \mathrm{C}$ was stated [47]. Similar to fructose, dehydration of glucose to 1,6 -anhydroglucose $[45,48]$ as well as cleavage of glucose to erythrose could take place $[45,49,53]$. The modeling made in the present 
work confirmed the existence of fructose and glucose decomposition to side products. Thus, when the value of $\mathrm{k}_{50}$ was equated with zero kinetic modeling of hydrolysis-dehydration of cellulose, as well as calculations on the other sugars gave higher yields of 5-HMF against the experimental data (Fig. S3). The constants of sugar consumption $\mathrm{k}_{30}, \mathrm{k}_{40}$ and $\mathrm{k}_{50}$ were determined from the available experimental and thermodynamic data via subtraction of constant values of monosaccharide transformations via confirmed pathways from the constant values of glucose, fructose and mannose total consumption, for example $\mathrm{k}_{30}=\mathrm{k}_{\mathrm{Glu}}-\mathrm{k}_{3}-\mathrm{k}_{34}$.

The experimental data presented in this work demonstrated the difference of the catalytic action between the solid Sibunit carbon and soluble sulfuric acid catalysts in cellulose hydrolysisdehydration. As stated above, the kinetic investigations were carried out at $180{ }^{\circ} \mathrm{C}$ and $\mathrm{pH}$ value of 2.7 in this work. The determined constant $\mathrm{k}_{2}\left(0.11 \mathrm{~min}^{-1}\right)$ of cellobiose hydrolysis to glucose over solid acid carbon catalyst was lower by a factor of 3.2 than the value observed previously in the presence of $\mathrm{H}_{2} \mathrm{SO}_{4}\left(\mathrm{pH} \mathrm{2.1,} 180^{\circ} \mathrm{C}\right)$ [55]. The total constant of glucose consumption through various pathways $\mathrm{k}_{\mathrm{glu}}\left(10.6 \cdot 10^{-3} \mathrm{~min}^{-1}\right)$ was higher than the value revealed previously in the presence of $\mathrm{H}_{2} \mathrm{SO}_{4}$ at $\mathrm{pH}$ of 2.1 and $180{ }^{\circ} \mathrm{C}$ [55]. J. F. Saeman reported the glucose degradation constant equal to $24.1 \cdot 10^{-3}$ under $180^{\circ} \mathrm{C}$ but $\mathrm{pH}$ value of ca. 1.1 [20]. The reaction constant $\mathrm{k}_{7}$ of 5 HMF hydration into levulinic and formic acids was in 25 times lower than the constant of 5-HMF degradation to side compounds $\left(\mathrm{k}_{8}=5.1 \cdot 10^{-3} \mathrm{~min}^{-1}\right)$. This can explain why the formation of levulinic acid is not significant over solid carbons while it is easily produced in the presence of soluble acid catalysts under close conditions (temperature and $\mathrm{pH}$ ) [18,56-58]. Thus, the data demonstrated that solid acid catalysts seems to be more suitable than soluble ones for the production of 5-HMF from the polysaccharides.

The system of differential equations was solved by the Mathcad 15.0 software with function Odesolve based on the Runge-Kutta method with an automatic step-size for solving. The developed kinetic model provided not only qualitative but also accurate enough quantitative description of cellulose hydrolysis-dehydration, as well as transformations of intermediates of the process under 
study (Fig. 2). It should be noted that the proposed model is applicable not only in the case of using cellulose as a substrate. Modeled kinetics also describes accurately the experiments where other intermediates glucose, fructose, mannose, and 5-HMF are substrates (Fig. 2).

\section{Conclusions}

The kinetic model which consisted of eighteen stages was proposed to predict cellulose hydrolysis-dehydration over a solid sulfonated Sibunit carbon catalyst in a batch reactor. The model described in the paper was based on the experimental data on hydrolysis-dehydration of cellulose the main process intermediates (cellobiose, glucose, fructose, mannose, 5-HMF, furfural, levulinic acid). Kinetic parameters of the reactions were revealed. Cellulose depolymerization was established to be limiting stage of cellulose processing, while hydrolysis of $\beta$-(1-4)-glycosidic bond in cellulose and oligosaccharides was a fast reaction. The difference of the catalytic action between the solid carbon and soluble acid catalysts in cellulose hydrolysis-dehydration was demonstrated. The degradation of 5-HMF into levulinic acid is not significant over solid carbons while it is the main reaction way in the presence of soluble acid catalysts under close conditions. Thus, solid acid carbon catalysts seems to be more suitable than soluble ones for the production of 5-HMF from sugars. The data on side conversions of monosaccharides were specified. The kinetic model of cellulose hydrolysis-dehydration was updated by adding side reactions of sugar decomposition and glucose conversion to mannose. A system of differential equations was solved using the Mathcad software. The computational model described well the chemical experimental data observed. 
Table 1. Constants of the cellulose hydrolysis-dehydration reactions

\begin{tabular}{|c|c|c|c|c|}
\hline \multirow{3}{*}{ Constant } & \multirow{3}{*}{ Interaction } & \multicolumn{3}{|c|}{ Constant values, $\min ^{-1}$} \\
\hline & & \multirow{2}{*}{ This work $^{[\mathrm{a}]}$} & \multicolumn{2}{|c|}{ Described in literature } \\
\hline & & & value & Ref. \\
\hline $\mathrm{k}_{0}$ & cellulose dissolution & $16 \cdot 10^{-3}$ & & \\
\hline $\mathrm{k}_{1}$ & Oligosaccharide hydrolysis & 0.11 & & \\
\hline $\mathrm{k}_{2}$ & hydrolysis of cellobiose to glucose & 0.11 & 0.356 & {$[55]^{[\mathrm{b}]}$} \\
\hline \multirow{5}{*}{ kglu } & \multirow{5}{*}{ the constant of glucose consumption via all the pathways } & \multirow{5}{*}{$10.6 \cdot 10^{-3}$} & $4.4 \cdot 10^{-3}$ & {$[55]^{[b]}$} \\
\hline & & & $3.0 \cdot 10^{-3}$ & {$[46]^{[\mathrm{c}]}$} \\
\hline & & & $12.1 \cdot 10^{-3}$ & {$[46]^{[\mathrm{d}]}$} \\
\hline & & & 0.225 & {$[28]^{[\mathrm{e}]}$} \\
\hline & & & $24.1 \cdot 10^{-3}$ & {$[20]^{[\mathrm{f}]}$} \\
\hline $\mathrm{k}_{3}$ & isomerization of glucose to fructose & $8.0 \cdot 10^{-3}$ & & \\
\hline $\mathrm{k}_{31}$ & izomerization of fructose to glucose & $3.07 \cdot 10^{-3}$ & & \\
\hline $\mathrm{k}_{30}$ & degradation of glucose to side products & $0.5 \cdot 10^{-3}$ & & \\
\hline \multirow{2}{*}{$\mathrm{k}_{\text {man }}$} & \multirow{2}{*}{ the constant of mannose consumption via all the pathways } & \multirow{2}{*}{$7.22 \cdot 10^{-3}$} & $7 \cdot 10^{-3}$ & {$[46]^{[\mathrm{g}]}$} \\
\hline & & & $18 \cdot 10^{-3}$ & {$[46]^{[\mathrm{h}]}$} \\
\hline $\mathrm{k}_{34}$ & isomerization of glucose to mannose & $1.6 \cdot 10^{-3}$ & & \\
\hline $\mathrm{k}_{43}$ & isomerization of mannose to glucose & $0.4 \cdot 10^{-3}$ & & \\
\hline $\mathrm{k}_{40}$ & degradation of mannose to side products & $2.0 \cdot 10^{-3}$ & & \\
\hline $\mathrm{k}_{\text {fru }}$ & the constant of fructose consumption via all the pathways & $4.37 \cdot 10^{-2}$ & & \\
\hline $\mathrm{k}_{4}$ & isomerization of fructose to mannose & $7.4 \cdot 10^{-3}$ & & \\
\hline
\end{tabular}




\begin{tabular}{|c|c|c|c|c|}
\hline $\mathrm{k}_{41}$ & isomerization of mannose to fructose & $4.82 \cdot 10^{-3}$ & & \\
\hline $\mathrm{k}_{50}$ & degradation of fructose to side products & $11.5 \cdot 10^{-3}$ & & \\
\hline $\mathrm{k}_{5}$ & dehydration of fructose to 5-HMF & $1.95 \cdot 10^{-2}$ & & \\
\hline $\mathrm{k}_{6}$ & dehydration of fructose to furfural & $2.23 \cdot 10^{-3}$ & & \\
\hline \multirow{2}{*}{$\mathrm{k}_{5 \mathrm{HMF}}$} & \multirow{2}{*}{ the constant of 5-HMF consumption via all the pathways } & \multirow{2}{*}{$5.3 \cdot 10^{-3}$} & $3 \cdot 10^{-3}$ & {$[46]^{[\mathrm{i}]}$} \\
\hline & & & $6 \cdot 10^{-3}$ & {$[46]^{[\mathrm{k}]}$} \\
\hline $\mathrm{k}_{7}$ & hydration of 5-HMF to levulinic and formic acids & $0.2 \cdot 10^{-3}$ & & \\
\hline $\mathrm{k}_{8}$ & degradation of 5-HMF to side products & $5.1 \cdot 10^{-3}$ & & \\
\hline K9 & hydration of furfural to formic and 4-hydrobutyric acids & $2.3 \cdot 10^{-3}$ & & \\
\hline $\mathrm{k}_{10}$ & degradation of formic acid to side products & $1.7 \cdot 10^{-3}$ & & \\
\hline $\mathrm{k}_{11}$ & degradation of furfural to side products & $2.1 \cdot 10^{-3}$ & & \\
\hline $\mathrm{k}_{12}$ & degradation of levulinic acid to side products & $1 \cdot 10^{-4}$ & & \\
\hline
\end{tabular}

$3 \mathrm{MPa} ;\left[\mathrm{b}\right.$ ] cellobiose substrate $10 \mathrm{~g} \cdot \mathrm{L}^{-1}, \mathrm{H}_{2} \mathrm{SO}_{4}$ catalyst, $\mathrm{pH} 2.1,180{ }^{\circ} \mathrm{C}$; [c] glucose substrate $1 \mathrm{~g} \cdot \mathrm{L}^{-1}, \mathrm{H}_{2} \mathrm{SO}_{4}$ catalyst, $\mathrm{pH} 2.5,170{ }^{\circ} \mathrm{C}$; [d] glucose 4 substrate $1 \mathrm{~g} \cdot \mathrm{L}^{-1}, \mathrm{H}_{2} \mathrm{SO}_{4}$ catalyst, $\mathrm{pH} 2.5,190{ }^{\circ} \mathrm{C}$; [e] $1.288 \% \mathrm{H}_{2} \mathrm{SO}_{4}$ catalyst, $\mathrm{pH} 0.85,200{ }^{\circ} \mathrm{C}$; [f] $0.8 \% \mathrm{H}_{2} \mathrm{SO}_{4}$ catalyst, $\mathrm{pH}$ of ca. $1.1,180{ }^{\circ} \mathrm{C}$; [g]

5 mannose substrate $2 \mathrm{~g} \cdot \mathrm{L}^{-1}, \mathrm{H}_{2} \mathrm{SO}_{4}$ catalyst, $\mathrm{pH} 2.5,170{ }^{\circ} \mathrm{C}$; [h] mannose substrate $2 \mathrm{~g} \cdot \mathrm{L}^{-1}, \mathrm{H}_{2} \mathrm{SO}_{4}$ catalyst, $\mathrm{pH} 2.5,190{ }^{\circ} \mathrm{C}$; [i] 5-HMF substrate $3 \mathrm{~g} \cdot \mathrm{L}^{-1}$,

$6 \mathrm{H}_{2} \mathrm{SO}_{4}$ catalyst, $\mathrm{pH} 2.5,170{ }^{\circ} \mathrm{C}$; [k] 5-HMF substrate $3 \mathrm{~g} \cdot \mathrm{L}^{-1}, \mathrm{H}_{2} \mathrm{SO}_{4}$ catalyst, $\mathrm{pH} 2.5,190{ }^{\circ} \mathrm{C}$. 


\section{References}

1. Negahdar L, Delidovich I, Palkovits R (2016) Aqueous-phase hydrolysis of cellulose and hemicelluloses over molecular acidic catalysts: Insights into the kinetics and reaction mechanism. Applied Catalysis B: Environmental 184:285-298. https://doi.org/10.1016/j.apcatb.2015.11.039

2. van Putten R-J, van der Waal JC, de Jong E, Rasrendra CB, Heeres HJ, de Vries JG (2013) Hydroxymethylfurfural, A Versatile Platform Chemical Made from Renewable Resources. Chemical Reviews 113 (3):1499-1597. https://doi.org/10.1021/cr300182k

3. Besson M, Gallezot P, Pinel C (2014) Conversion of Biomass into Chemicals over Metal Catalysts. Chemical Reviews 114 (3):1827-1870. https://doi.org/10.1021/cr4002269

4. Yang P, Kobatashi N, Fukuoka A (2011) Recent Developments in the Catalytic Conversion of Cellulose into Valuable Chemicals. Chinese Journal of Catalysis 32 (5):716-722. https://doi.org/10.1016/S1872-2067(10)60232-X

5. Bhaumik P, Dhepe PL (2016) Solid acid catalyzed synthesis of furans from carbohydrates. Catalysis Reviews 58 (1):36-112. https://doi.org/10.1080/01614940.2015.1099894

6. Gromov NV, Taran OP, Delidovich IV, Pestunov AV, Rodikova YA, Yatsenko DA, Zhizhina EG, Parmon VN (2016) Hydrolytic oxidation of cellulose to formic acid in the presence of Mo-V-P heteropoly acid catalysts. Catalysis Today 278:74-81. https://doi.org/10.1016/j.cattod.2016.03.030

7. Wolfel R, Taccardi N, Bosmann A, Wasserscheid P (2011) Selective catalytic conversion of biobased carbohydrates to formic acid using molecular oxygen. Green Chemistry 13 (10):27592763. https://doi.org/10.1039/C1GC15434F

8. Maki-Arvela P, Holmbom B, Salmi T, Murzin DY (2007) Recent Progress in Synthesis of Fine and Specialty Chemicals from Wood and Other Biomass by Heterogeneous Catalytic Processes. Catalysis Reviews 49 (3):197-340. https://doi.org/10.1080/01614940701313127

9. Liu M, Deng W, Zhang Q, Wang Y, Wang Y (2011) Polyoxometalate-supported ruthenium nanoparticles as bifunctional heterogeneous catalysts for the conversions of cellobiose and cellulose 
into sorbitol under mild conditions. Chemical Communications 47 (34):9717-9719. https://doi.org/10.1039/C1CC12506K

10. Fukuoka A, Dhepe PL (2006) Catalytic Conversion of Cellulose into Sugar Alcohols.

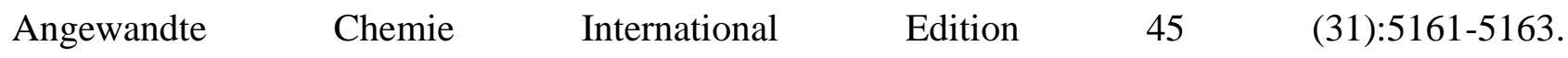
https://doi.org/10.1002/anie.200601921

11. Gromov NV, Medvedeva TB, Taran OP, Timofeeva MN, Said-Aizpuru O, Panchenko VN, Gerasimov EY, Kozhevnikov IV, Parmon VN (2020) The main factors affecting the catalytic properties of Ru/Cs-HPA systems in one-pot hydrolysis-hydrogenation of cellulose to sorbitol. Applied Catalysis A: General 595:117489. https://doi.org/10.1016/j.apcata.2020.117489

12. Gallezot P (2012) Conversion of biomass to selected chemical products. Chemical Society Reviews 41:1538-1558. https://doi.org/10.1039/C1CS15147A

13. Serrano-Ruiz JC, Braden DJ, West RM, Dumesic JA (2010) Conversion of cellulose to hydrocarbon fuels by progressive removal of oxygen. Applied Catalysis B: Environmental 100 (1):184-189. https://doi.org/10.1016/j.apcatb.2010.07.029

14. Rackemann DW, Doherty WOS (2011) The conversion of lignocellulosics to levulinic acid. Biofuels, Bioproducts and Biorefining 5 (2):198-214. https://doi.org/10.1002/bbb.267

15. Onda A, Ochi T, Yanagisawa K (2008) Selective hydrolysis of cellulose into glucose over solid acid catalysts. Green Chemistry 10 (10):1033-1037. https://doi.org/10.1039/B808471H

16. Kobayashi H, Komanoya T, Hara K, Fukuoka A (2010) Water-tolerant mesoporous-carbonsupported ruthenium catalysts for the hydrolysis of cellulose to glucose. ChemSusChem 3 (4):440443. https://doi.org/10.1002/cssc.200900296

17. P Pang J, Wang A, Zheng M, Zhang T (2010) Hydrolysis of cellulose into glucose over carbons sulfonated at elevated temperatures. Chemical Communications 46:6935-6937. https://doi.org/10.1039/c0cc02014a

18. Gromov NV, Medvedeva TB, Taran OP, Bukhtiyarov AV, Aymonier C, Prosvirin IP, Parmon VN (2018) Hydrothermal Solubilization-Hydrolysis-Dehydration of Cellulose to Glucose and 5- 
Hydroxymethylfurfural Over Solid Acid Carbon Catalysts. Topics in Catalysis 61 (18):1912-1927. https://doi.org/10.1007/s11244-018-1049-4

19. Gromov NV, Taran OP, Parmon VN (2018) CHAPTER 3 Catalysts for Depolymerization of Biomass. In: Sustainable Catalysis for Biorefineries. The Royal Society of Chemistry, pp 65-97. https://doi.org/10.1039/9781788013567-000655

20. Saeman JF (1945) Kinetics of Wood Saccharification - Hydrolysis of Cellulose and Decomposition of Sugars in Dilute Acid at High Temperature. Industrial \& Engineering Chemistry 37 (1):43-52. https://doi.org/10.1021/ie50421a009

21. Jacobsen SE, Wyman CE (2000) Cellulose and hemicellulose hydrolysis models for application to current and novel pretreatment processes. Applied Biochemistry and Biotechnology 84 (1):81-96. https://doi.org/10.1385/ABAB:84-86:1-9:81

22. Abasaeed AE, Lee YY, Watson JR (1991) Effect of transient heat transfer and particle size on acid hydrolysis of hardwood cellulose. Bioresource Technology 35 (1):15-21. https://doi.org/10.1016/0960-8524(91)90077-W

23. Orozco A, Ahmad M, Rooney D, Walker G (2007) Dilute Acid Hydrolysis of Cellulose and Cellulosic Bio-Waste Using a Microwave Reactor System. Process Safety and Environmental Protection 85 (5):446-449. https://doi.org/10.1205/psep07003

24. Mok WS, Antal MJ, Varhegyi G (1992) Productive and parasitic pathways in dilute acidcatalyzed hydrolysis of cellulose. Industrial \& Engineering Chemistry Research 31 (1):94-100. https://doi.org/10.1021/ie00001a014

25. Rogalinski T, Ingram T, Brunner G (2008) Hydrolysis of lignocellulosic biomass in water under elevated temperatures and pressures. The Journal of Supercritical Fluids 47 (1):54-63. https://doi.org/10.1016/j.supflu.2008.05.003

26. Mosier NS, Ladisch CM, Ladisch MR (2002) Characterization of acid catalytic domains for cellulose hydrolysis and glucose degradation. Biotechnology and Bioengineering 79 (6):610-618. https://doi.org/10.1002/bit.10316 
27. Camacho F, González-Tello P, Jurado E, Robles A (1996) Microcrystalline-cellulose hydrolysis with concentrated sulphuric acid. Journal of Chemical Technology \& Biotechnology 67 (4):350356. https://doi.org/10.1002/(SICI)1097-4660(199612)67:4<350::AID-JCTB564>3.0.CO;2-9

28. Malester IA, Green M, Shelef G (1992) Kinetics of dilute acid hydrolysis of cellulose originating from municipal solid wastes. Industrial \& Engineering Chemistry Research 31 (8):19982003. https://doi.org/10.1021/ie00008a023

29. Franzidis J-P, Porteous A, Anderson J (1982) The acid hydrolysis of cellulose in refuse in a continuous reactor. Conservation \& Recycling 5 (4):215-225. https://doi.org/10.1016/0361$\underline{3658(82) 90050-9}$

30. Abatzoglou N, Bouchard J, Chornet E, Overend RP (1986) Dilute acid depolymerization of cellulose in aqueous phase: Experimental evidence of the significant presence of soluble oligomeric intermediates. The Canadian Journal fo Chemical Engenering 64 (5):781-786. https://doi.org/10.1002/cjce.5450640510

31. SriBala G, Vinu R (2014) Unified Kinetic Model for Cellulose Deconstruction via Acid Hydrolysis. Industrial \& Engineering Chemistry Research 53 (21):8714-8725. https://doi.org/10.1021/ie5007905

32. Bouchard J, Garnier G, Vidal P, Chornet E, Overend RP (1990) Characterization of depolymerized cellulosic residues. Wood Science and Technology 24 (2):159-169. https://doi.org/10.1007/BF00353250

33. Xiang Q, Kim JS, Lee YY (2003) A comprehensive kinetic model for dilute-acid hydrolysis of $\begin{array}{llllll}\text { cellulose. Applied } & \text { Biochemistry and } 337-352 .\end{array}$ https://doi.org/10.1385/ABAB:106:1-3:337

34. Fagan RD, Grethlein HE, Converse AO, Porteous A (1971) Kinetics of the acid hydrolysis of cellulose found in paper refuse. Environmental Science \& Technology 5 (6):545-547. https://doi.org/10.1021/es60053a006 
35. Xiang Q, Lee YY, Pettersson PO, Torget RW (2003) Heterogeneous aspects of acid hydrolysis of $\alpha$-cellulose. Applied Biochemistry and Biotechnology $107 \quad$ (1):505-514. https://doi.org/10.1007/978-1-4612-0057-4_42

36. Conner AH, Wood BF, Hill CG, Harris JF (1986). In: Young RA, Rowell RM (eds) Cellulose: Structure, Modification and Hydrolysis. J. Wiley \& Sons, New York, pp 281-296

37. Bahari A, Baig MN, Leeke GA, Bowra S, Santos RCD (2014) Subcritical water mediated hydrolysis of cider spent yeast: Kinetics of HMF synthesis from a waste microbial biomass. Industrial Crops and Products 61:137-144. https://doi.org/10.1016/j.indcrop.2014.06.031

38. Cantero DA, Bermejo MD, Cocero MJ (2015) Governing Chemistry of Cellulose Hydrolysis in Supercritical Water. ChemSusChem 8 (6):1026-1033. https://doi.org/10.1002/cssc.201403385

39. Gurgel LVA, Marabezi K, Zanbom MD, Curvelo AAdS (2012) Dilute Acid Hydrolysis of Sugar Cane Bagasse at High Temperatures: A Kinetic Study of Cellulose Saccharification and Glucose Decomposition. Part I: Sulfuric Acid as the Catalyst. Industrial \& Engineering Chemistry Research 51 (3):1173-1185. https://doi.org/10.1021/ie2025739

40. Gromov NV, Taran OP, Semeykina VS, Danilova IG, Pestunov AV, Parkhomchuk EV, Parmon VN (2017) Solid Acidic $\mathrm{NbO}_{\mathrm{x}} / \mathrm{ZrO}_{2}$ Catalysts for Transformation of Cellulose to Glucose and 5Hydroxymethylfurfural in Pure Hot Water. Catalysis Letters 147 (6):1485-1495. https://doi.org/10.1007/s10562-017-2056-y

41. Feather MS, Harris JF (1973) Dehydration Reactions of Carbohydrates ${ }^{\circ}$. In: Tipson RS, Derek $\mathrm{H}$ (eds) Advances in Carbohydrate Chemistry and Biochemistry, vol Volume 28. Academic Press, pp 161-224. http://dx.doi.org/10.1016/S0065-2318(08)60383-2

42. Bobleter O, Bonn G (1983) The hydrothermolysis of cellobiose and its reaction-product dglucose. Carbohydrate Research 124 (2):185-193. https://doi.org/10.1016/0008-6215(83)88454-7 43. Ponder GR, Richards GN (1993) Pyrolysis of inulin, glucose and fructose. Carbohydrate Research 244 (2):341-359. https://doi.org/10.1016/0008-6215(83)85012-5 
44. De Wit G, Kieboom APG, van Bekkum H (1979) Enolisation and isomerisation of monosaccharides in aqueous, alkaline solution. Carbohydrate Research 74 (1):157-175. https://doi.org/10.1016/S0008-6215(00)84773-4

45. Kabyemela BM, Adschiri T, Malaluan RM, Arai K (1999) Glucose and Fructose Decomposition in Subcritical and Supercritical Water: Detailed Reaction Pathway, Mechanisms, and Kinetics. Industrial \& Engineering Chemistry Research 38 (8):2888-2895. https://doi.org/10.1021/ie9806390

46. Baugh KD, McCarty PL (1988) Thermochemical pretreatment of lignocellulose to enhance methane fermentation: I. Monosaccharide and furfurals hydrothermal decomposition and product formation rates. Biotechnology and Bioengineering $31 \quad$ (1):50-61. https://doi.org/10.1002/bit.260310109

47. Bonn G, Bobleter O (1983) Determination of the hydrothermal degradation products of D-(U14C) glucose and D-(U-14C) fructose by TLC. Journal of Radioanalytical Chemistry 79 (2):171177. https://doi.org/10.1007/BF02518929

48. Klinger D, Vogel H (2010) Influence of process parameters on the hydrothermal decomposition and oxidation of glucose in sub- and supercritical water. Journal of Supercritical Fluids 55 (1):259270. https://doi.org/10.1016/j.supflu.2010.06.004

49. Sasaki M, Kabyemela B, Malaluan R, Hirose S, Takeda N, Adschiri T, Arai K (1998) Cellulose hydrolysis in subcritical and supercritical water. Journal of Supercritical Fluids 13 (1-3):261-268. https://doi.org/10.1016/S0896-8446(98)00060-6

50. Jiang C-W, Zhong X, Luo Z-H (2014) An improved kinetic model for cellulose hydrolysis to 5hydroxymethylfurfural using the solid $\mathrm{SO}_{4}{ }^{2-} / \mathrm{Ti}-\mathrm{MCM}-41$ catalyst. RSC Advances 4 (29):1521615224. https://doi.org/10.1039/C4RA00167B

51. Tewari YB, Goldberg RN (1984) Thermodynamics of the conversion of aqueous glucose to fructose. Journal of Solution Chemistry 13 (8):523-547. https://doi.org/10.1007/bf00647222 
52. Delidovich I, Gyngazova MS, Sánchez-Bastardo N, Wohland JP, Hoppe C, Drabo P (2018) Production of keto-pentoses via isomerization of aldo-pentoses catalyzed by phosphates and recovery of products by anionic extraction. Green Chemistry 20 (3):724-734. https://doi.org/10.1039/c7gc03077k

53. Aida TM, Tajima K, Watanabe M, Saito Y, Kuroda K, Nonaka T, Hattori H, Smith Jr RL, Arai $\mathrm{K}$ (2007) Reactions of d-fructose in water at temperatures up to $400{ }^{\circ} \mathrm{C}$ and pressures up to 100 $\begin{array}{llllll}\text { MPa. The Journal of } & \text { Supercritical } & \text { Fluids } 110-119 .\end{array}$ https://doi.org/10.1016/j.supflu.2006.12.017

54. Antal Jr MJ, Mok WSL, Richards GN (1990) Mechanism of formation of 5-(hydroxymethyl)-2furaldehyde from d-fructose and sucrose. Carbohydrate Research 199 (1):91-109. https://doi.org/10.1016/0008-6215(90)84096-D

55. Bobleter O, Schwald W, Concin R, Binder H (1986) Hydrolysis of Cellobiose in Dilute Sulpuric Acid and Under Hydrothermal Conditions. Journal of Carbohydrate Chemistry 5 (3):387-399. https://doi.org/10.1080/07328308608058843

56. Mukherjee A, Dumont M-J, Raghavan V (2015) Review: Sustainable production of hydroxymethylfurfural and levulinic acid: Challenges and opportunities. Biomass and Bioenergy 72:143-183. http://dx.doi.org/10.1016/j.biombioe.2014.11.007

57. Horvat J, Klaić B, Metelko B, Šunjić V (1985) Mechanism of levulinic acid formation. Tetrahedron Letters 26 (17):2111-2114. https://doi.org/10.1016/S0040-4039(00)94793-2

58. van Dam HE, Kieboom APG, van Bekkum H (1986) The Conversion of Fructose and Glucose in Acidic Media: Formation of Hydroxymethylfurfural. Starch - Stärke 38 (3):95-101. https://doi.org/10.1002/star.19860380308 